\title{
Thalassaemia Prevention: Bangladesh Perspective - A Current Update
}

\author{
SARABON TAHURA ${ }^{1}$, MD. SELIMUZZAMAN ${ }^{2}$, WAQAR AHMED KHAN ${ }^{3}$
}

\begin{abstract}
Thalassaemias are a group of autosomal recessive disorder and the most common inherited disease worldwide with a wide geographical variation in incidence. Bangladesh, a developing country, having a population over 160 million. World Health Organization (WHO) has estimated that $3 \%$ of our population carries $\beta$ - thalassaemia and $4 \%$ of population carries $\mathrm{Hb}-\mathrm{E}$ in Bangladesh. But recently Khan WA showed that carrier status of $\mathrm{Hb}-\mathrm{E}$ is $6.1 \%$ and as high as $41.7 \%$ in tribal school children in Bangladesh. Since Thalassaemia is a severe and incurable disease, it is only manageable when it is prevented. The WHO has advocated and promoted the programs for thalassaemia prevention from the early 1970s. Several countries have already set up comprehensive national thalassaemia prevention programs but in our country most of the population is unware of this hereditary disease. The rapidly growing number of children diagnosed as thalassaemia in Bangladesh clearly indicate that thalassaemia will be a emerging health burden for our country. So, we need to prevent thalassaemia before it's too late by comprehensive national integrated prevention programs which include public awareness and education, carrier screening, genetic counseling, premarital screening and prenatal diagnosis. Thalassaemia prevention program has become a community concern as it affects marriage practices and reproduction. So, ethical issues need to be addressed for proper implementation of this by government policy, central control and co-ordination according to the local structures, social values, religious laws and cultural tradition of our country.
\end{abstract}

Key words: Thalassaemia, Prevention, Update.

\section{Introduction}

The thalassaemias are a group of hereditary disorder caused by reduction or absent production of one or more of the globin chain that make up the hemohlobin $(\mathrm{Hb})$ tetramers. Worldwide thalassaemias are the commonest autosomal recessive disorders. ${ }^{1,2,3}$ About $60,000-70,000$ children are born each year with severe

1. Assistant Professor, Department of Pediatric Hematology and Oncology, Bangladesh Institute of Child Health $(\mathrm{BICH})$, Dhaka Shishu (Children) Hospital, Dhaka.

2. Professor \& Head, Department of Pediatric Hematology and Oncology, Bangladesh Institute of Child Health (BICH), Dhaka Shishu (Children) Hospital, Dhaka.

3. Chief Co-ordinator, Department of Biochemistry \& Molecular Biology, Dhaka Shishu (Children) Hospital, Dhaka.

Correspondence: Sarabon Tahura, Assistant Professor, Department of Pediatric Hematology and Oncology, Bangladesh Institute of Child Health (BICH), Dhaka Shishu (Children) Hospital, Dhaka, E-mail: drsarabon@ yahoo.com. form of thalasaemias. ${ }^{4}$ and unfortunately most affected children are born in low resource areas of the world. ${ }^{5}$

Bangladesh, a developing country, has achieved appreciable reduction in infant and under- 5 mortality ${ }^{6}$ by combating against malnutrition, infectious disease and by improving health system but hereditary disorder receive little attention yet. It is presumed that approximately 6000 thalassaemic children are born each year in Bangladesh. ${ }^{7}$ but most of the population is unaware of this hereditary disease, only a few cases are diagnosed. It has also been estimated that, worldwide, 9 million carriers become pregnant annually and 1.33 million pregnancies are at risk for a thalassaemia major condition ${ }^{1,3}$ Bangladesh, having population of over 160 million, there is no national data about the number of thalassaemia patient in the country. Khan et $\mathrm{al}^{8}$ estimated that existing thalassaemic patient in Bangladesh is about 1 lac 
and suspected total number of $\beta$-thalassaemia major and $\mathrm{Hb}-\mathrm{E} \beta$-thalassaemia born around 1040 and 6443 per year respectively in our country. Rahman et al ${ }^{9}$ found $\mathrm{Hb} E \beta$-thalassaemia in $67 \%$ of total cases in a study done in Dhaka. In another study, conducted in Dinajpur Medical college hospital, Hasan et al observed that among 60 patients, $\mathrm{Hb}$ E Trait was $41.67 \%$ and $\mathrm{Hb} \mathrm{E}$ disease was $30 \%$ and $\mathrm{Hb}^{2}$-thalassaemia and $\beta$-thalassaemia trait was $23.33 \%, 3.33 \% \%$ respectively. ${ }^{10}$ There is also lack of definitive data regarding existing thalassaemia carrier in our country. A conservative WHO report has shown that $3 \%$ of population carries $\beta$-thalassaemia and $4 \%$ carries $\mathrm{Hb}$ $\mathrm{E}$ in Bangladesh ${ }^{7}$. But according to Khan et all ${ }^{8}$ carrier status of $\mathrm{Hb}-\mathrm{E}$ is $6.1 \%$ and as high as $41.7 \%$ in tribal school children in Bangladesh. Farhana et al ${ }^{11}$ found $17.39 \% \mathrm{Hb} E$ trait and $13.04 \% \mathrm{Hb}$ E disease in their study done in Bangladesh Institute of Rehabilitation in Diabetes Endocrine and Metabolic disorder (BIRDEM). So, it is explicable that thalassaemia will be a emerging health burden for our country. ${ }^{7}$ As, Thalassaemia is a hereditary disease, it is only manageable when it is prevented. In the late 1970s pilot population programs directed to prevent $\beta$ thalassaemia major by carrier screening, counseling and prenatal diagnosis started in several at-risk populations in the Mediterranean area (Cyprus, Sardinia, several regions of Continental Italy). ${ }^{12} \mathrm{At}$ present, several countries like Italy, Greece, Cyprus, UK, France, Iran, Thailand, Australia, Singapore, Taiwan, Hong Kong, Cuba and also in Northern Europe ( Netherlands, Belgium and Germany) $)^{13}$ have set up comprehensive national thalassaemia prevention program. Cyprus and Sardinia both are the unique examples for successful thalassaemia prevention. In Sardinia declination of birth rate of thalassaemia major from 1:250 live birth to 1:1660 has been reported in 2009 with an effective prevention of $85 \%$ of cases $^{14}$ and similar results have also been reported in Cyprus. ${ }^{15}$ But in Bangladesh, there is no national thalassaemia prevention program yet.

\section{The Elements of Thalassaemia Prevention}

\section{A. Public Awareness and Education:}

Raising awareness and education to health personnel, groups at risk, population at large and also among policymaker is the critical prerequisite for thalassaemia prevention. ${ }^{14}$ Mass population education should be modulated according to the social values, religious laws and cultural characteristics of the country. In Srilanka, Mudiyanse et el ${ }^{16}$ observed, inspite of free facilities for thalassaemia screening, uptake was very poor. So, their recommendation was more intensive monitoring and strengthening of education programs. Alwan et al ${ }^{17}$ also recommend intensive education of health professionals as well as the population at large in the field of preventive measures of thalassaemia.

\section{B. Carrier detection and Premarital Screening:}

Several procedures have been proposed for thalassaemia carrier detection ${ }^{18}$. These are CBC, $\mathrm{Hb}$ Electrophoresis and PCR based analysis. In South Asian rural area one tube fragility test (OF) associated with dichlorophenol indophenol (DCIP) dye test is used to detect the presence of $\mathrm{Hb} \mathrm{E}$, which is the most common in this region ${ }^{19}$. Those individual who resulting positive at this screening test are further investigate by quantitative $\mathrm{HbA}_{2}$ determination for identifying heterozygous $\beta$-thalassaemia. But, one tube fragility test may miss those $\beta$-thalassaemia heterozygotes who coinherited with $\beta$-thalassaemia ${ }^{20}$. According to Cao et al ${ }^{14}$ a carrier detection procedure should be designed to avoid missing any couple at risk and their recommendation is quantitative evaluation of $\mathrm{HbA}_{2}$ for carrier detection, which may be obtained by electrophoresis or by high pressure liquid chromatography (HPLC). HPLC has the additional advantages to quantitate $\mathrm{HbF}$ and to detect clinical relevant $\mathrm{Hb}$ variants which may interact with $\beta$ thalassaemia heterozygosity. ${ }^{14}$ Now a days, detection of the most frequent mutations or deletions of $\beta$-globin and $\beta$-globin gene are detected by a PCRbased procedure among the most commonly used commercially available RDB (Reverse oligonucleotide hybridization) analysis ${ }^{21}$ and allele-specific amplification ARMS (Amplification refractory mutation system) analysis. ${ }^{22}$

Now, in many countries premarital carrier screening is being performed on a voluntary basis. ${ }^{12}$ In Cyprus, the Orthodox church requires a certificate providing that screening for ${ }^{2}$-thalassaemia has been performed before marriage, but allows the final decision on marriage and reproduction option to be left to the couple. ${ }^{12,23}$ In a number of Muslim countries including Saudi Arabia, Iran, United Arab Emirates, Bahrain, Tunisia, Lebanon, Qatar and Gaza Strip ${ }^{24,25}$ the national premarital program are mandatory and aimed at limiting carrier marriage.

\section{Genetic Counseling to the couples at risk:}

Genetic counseling plays the most important part in thalassaemia prevention program. Agenetic counselor must be trained in molecular genetics of thalassaemia and should have sufficient experience and expertise to communicate with and give detail informations about 
the disease to the patients and family members. ${ }^{26}$ According to international rules, counseling has been performed in a non-directive way but direct to the counselee's corner and is based on a private interview. Genetic counseling includes -

1. Detail informations and explanations of nature and prognosis of the disorder.

2. Estimation of genetic risks for the parents

If only one parent is thalassaemia carrier (trait), the following can occur (fig-1):

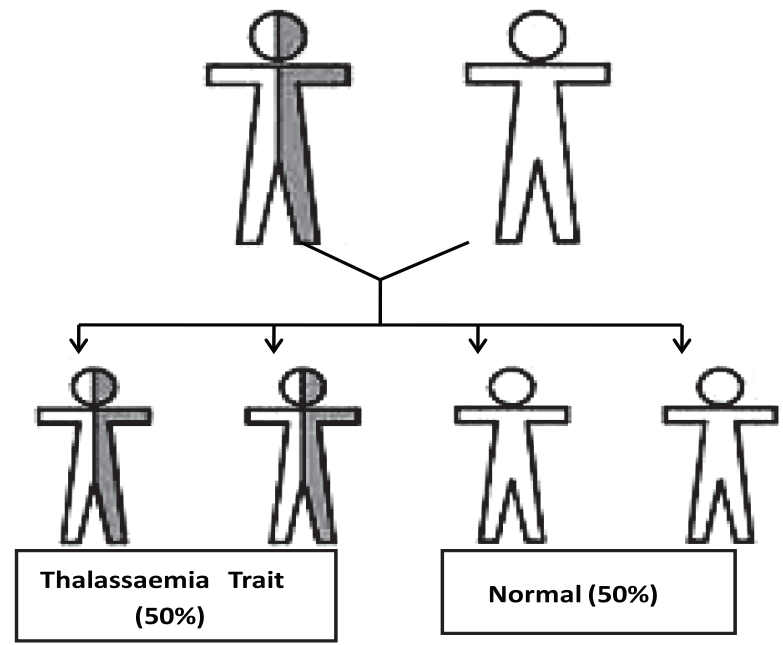

Fig-1: Possibility in each pregnancy if one parent is carrier

- $50 \%$ chance of having a child with thalassaemia carrier (trait)

- $50 \%$ chance of having a normal child

- None of their children will get thalassaemia major

If both parents have thalassaemia carrier (trait), the following can occur (Fig-2):

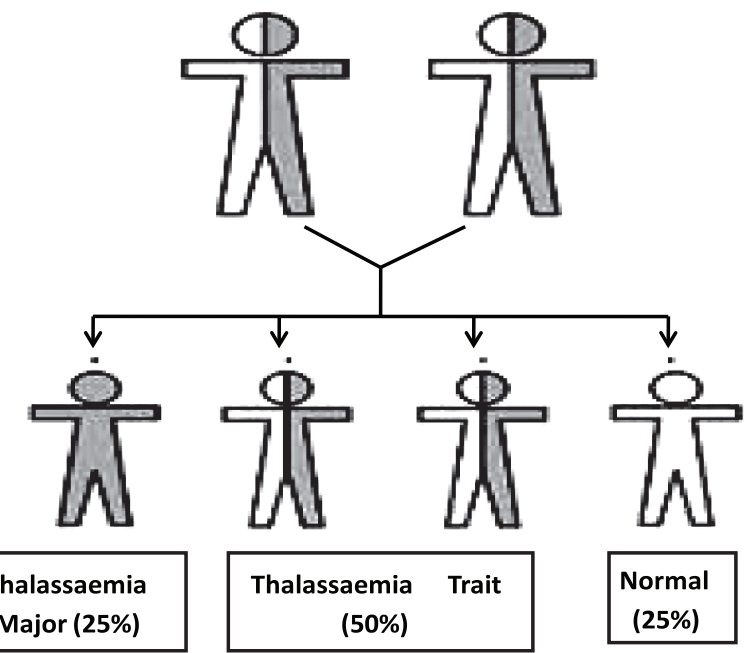

Fig-2: Possibility in each pregnancy if both parents are carrier
- $25 \%$ chance of having a child with thalassaemia major

- $50 \%$ chance of having a child with thalassaemia carrier

- $25 \%$ chance of having a normal child

The chances are the same in each pregnancy, no matter how many children the couple has.

3. Providing informations about various available options for prenatal diagnosis

4. Giving support for making the right decision but respect and priority should be given towards the wishes and choice of the couple.

D. Prenatal Diagnosis:

Thalassaemia detection is possible directly by the analysis of amplified DNA collected from fetal trophoblast or amniotic fluid cells. Now-a-days, prenatal diagnosis by DNA analysis is available in Mediterranean area ( Cyprus, Sardinia, several regions of Continental Italy) ${ }^{15}$, Northern Europe (Netherland, Belgium and Germany), Northern and South America, Hongkong, Taiwan, China, Indonesia, Malaysia, Jordan. ${ }^{27}$ Prenatal diagnosis service has also been introduced even in many developing countries. ${ }^{3}$ Fetal DNA analysis is done by one of the two methods described here

\section{Chorionic villus sampling (Fig 3):}

By needle insertion through the abdominal wall under ultrasound guidance, a small amount of chorionic villi material which is the same genetic makeup as the fetus is aspirated for DNA analysis. ${ }^{28}$ This is done around 10 weeks of pregnancy.

CVS is preferable as it is done in the first trimester of pregnancy within the time limit laid down by abortion law in many countries. It also reduces the emotional stress of parents and complications of late termination of pregnancy.

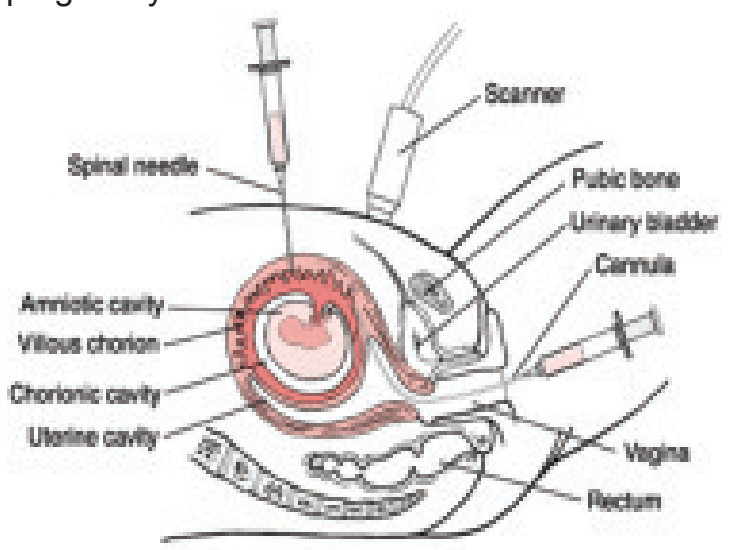

Fig.-3: Chorionic villus sampling (CVS) 


\section{Amniocentesis (Fig 4)}

A small needle is inserted through the abdomen under ultrasound guidance and about $15-20 \mathrm{ml}$ of fluid from amniotic cavity surrounding the fetus is aspirated for DNA analysis. ${ }^{28}$ This is done from 16 weeks of pregnancy.

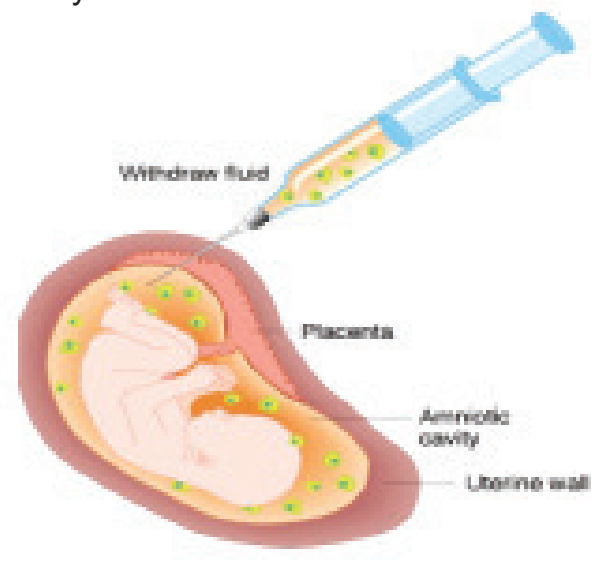

Fig-4: Amniocentesis

Pre-implantation and Pre-conceptional diagnosis Recent unique progress in molecular genetics to analyze the genotype of a single cell along with advancement in assisted reproduction techniques now made possible to detect Pre-implantation and Preconceptional diagnosis of thalassaemia. It is performed either by biopsy of one to two blastomeres in eight-cell embryos after in vitro fertilization or by biopsy of trophectoderm cells from blastocyst. ${ }^{29}$ Diagnosis is obtained by multiple nested PCR analysis to detect the mutations as well as polymorphic allels at the $\beta$-globin cluster. ${ }^{30,31}$ Now-a-days these techniques are widely available in continental Greece $^{29}$, Cyprus $^{30}$ and also in China. ${ }^{32}$ Termination at this stage may diminish the moral, religious and emotional stress of the parents.

\section{Prenatal diagnosis by noninvasive procedure}

Nowadays several noninvasive procedures have been attempted to make fetal diagnosis by analysis of fetal cells in maternal circulation. ${ }^{33}$ Lun et al ${ }^{34}$ performed analysis of fetal DNA in maternal plasma for prenatal diagnosis of thalassaemia. Recently, prenatal $\beta$ thalassaemia is diagnosed by the Lo group with next generation sequencing (paired and massively parallel sequencing) of fetal and maternal DNA genomes which present in maternal plasma. ${ }^{35}$

\section{E. Extended Family Screening:}

Relatives of thalassaemic child are at risk of being a carrier. ${ }^{36}$ So, they should be under extended family screening to detect carriers to prevent birth of thalassaemic children. For these the parents of thalassaemic children need regular interview and awareness raising counseling to share information with their relatives for motivate them and identify the barriers for screening test.

Bangladesh perspective: Current status, challenge and elucidation

Bangladesh is a resource limited, developing country where most of the people are Muslim, culturally sensitive and majority of them are unaware about thalassaemia due to lack of knowledge about this hereditary disease. For last few decays, health system and facilities have improved a lot in our country but, there is no thalassaemia prevention program at national level yet and there is no comprehensive Thalassaemia center in any Government medical college nor in any govt. healthcare center. Only in Dhaka Shishu (Children) Hospital, there is a complete thalassaemia center providing integrated facilities including thalassaemia diagnosis, treatment, counseling, carrier screening, and prenatal diagnosis. Bangabondhu Shekh Mujib Medical University (BSMMU), Dhaka Medical college Hospital and some private organizations also provide some of these services in different scale but all these facilities are only Dhaka based and are very insufficient for the total vast population of the country.

Bangladesh observes 'Thalassaemia day' on the $8^{\text {th }}$ May with all over the world. On that day Dhaka Shishu (Children) Hospital, other institutes and some private organizations arrange various activities for raising awareness about thalassaemia. At present existing thalassaemia societies in Bangladesh are Bangladesh Thalassaemia Samity, Bangladesh Thalassaemia Foundation, Thalassaemia Welfare Center, Lab One Foundation of Thalassaemia, Thalassaemia Society of Doctors, Thalassaemia Welfare Society. Younger generation of the country are also coming forward like youth club etc to create awareness about this hereditary disease. But all these are inadequate for the huge population of the country.

As, the $1^{\text {st }}$ and fundamental step of thalassaemia prevention is raising public awareness and education, we must be attentive about this. Intensive education about thalassaemia and the way of its prevention should be directed towards the health personnel (physicians, nurses, health workers, family planning workers) and also the population at risk by arranging periodic meetings, seminar and CME programs. On the other hand, to raise general population awareness, detail informations regarding thalassaemia should be disseminated through mass media of the country (radio, 
television, newspaper) and by social networking (facebook, twitter etc.). Posters, festoons, informational leaflets, booklets should be left not only in counseling rooms but also at every health care centers, family planning clinics and even at marriage registry offices.

Basic information about thalassaemia including measures of prevention need to be introduced in the formal educational curriculum of our country at the secondary school level. It may play a very successful role in enforcing the knowledge of thalassaemia among the young generation and eventually among their other family members.

The next important step for thalassaemia prevention is carrier screening which should be directed towards the couple at risk, premarital screening and extended family screening at risk group. A unique model example regarding thalassaemia prevention is Cyprus where carrier screening is mandatory and certificate of ${ }^{2}$ thalassaemia screening requires before marriage. In China prenatal screening is compulsory to obtain marriage permission by marriage law office. ${ }^{37}$ In our country there is no national thalassaemia screening program yet. Khan et $\mathrm{al}^{8}$ conducted a study to detect carrier status in different divisions of Bangladesh (fig.-5).

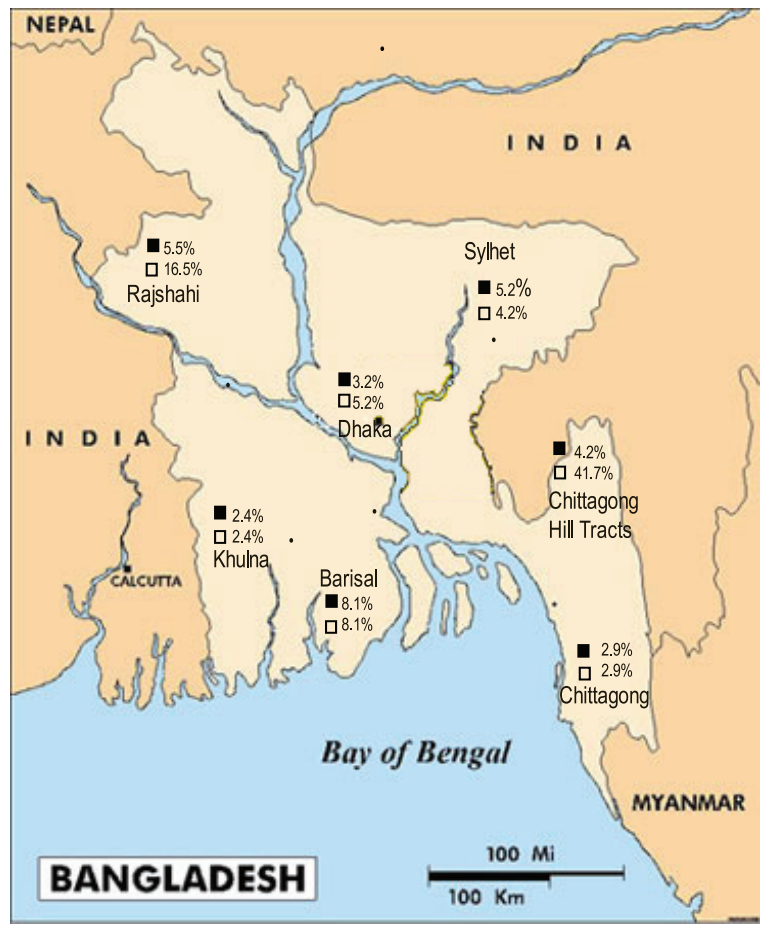

- Beta Thalassemia trait
Hb E trait

Fig-5: Map showing the distribution of Beta Thalassemia carrier (trait) and $\mathrm{Hb}$ E carrier (trait) in Six Divisions of Bangladesh
Current situation demands a structured national thalassaemia carrier screening program in Bangladesh.

Dhaka Shishu (Children) Hospital Thalassaemia center has started a DNA lab from 2014 for prenatal DNA analysis by CVS and Amniotic sampling to detect the status of fetus where the parents are thalassaemia carrier. Already 46 prenatal thalassaemia diagnosis was performed there and this DNA lab is ongoing successfully. Very recently Sultana et $\mathrm{al}^{38}$ has conducted genotypic profile of $\beta$ thalassaemia mutation in the population of Bangladesh and found great variability (heterogenicity) of $\beta$ thalassaemia in Bangladesh and they identified IVS1-5: G>C is the most polymorphism for $\beta$ thalassaemia and a combination of IVS1-5: $G>C$ and CD 26/E: $G>A$ is the most common polymorphism for $E-\beta$ thalassaemia located within HBB: c-92 to IVS- 2-81 in our country. This lacation may be used as biomarker for carrier screening, genetic counseling and for establishment of a comprehensive allele specific prenatal diagnosis kit for detection of $\beta$ thalassaemia in Bangladesh. Fetal DNA analysis for prenatal thalassaemia detection was also done in BSMMU for a very brief period of time. Recently 'DNA solution, Bangladesh' a private organization, has started prenatal DNA analysis but is very costly and unaffordable for majority poor population of the country. But Prenatal diagnosis must be made available nationwide for successful thalassaemia prevention. Technical advancements regarding fetal cell analysis in maternal plasma should be introduced in our country. This non-invasive prenatal diagnosis technique may reduce the fear and ultimately increase the acceptance of achieving prenatal thalassaemia screening. Marriage between two carriers must be avoided also.

The most sensitive and crucial issue after prenatal diagnosis is to take decision about the affected fetus. In a number of Muslim countries including Saudi Arabia, United Arab Emirates, Iran, Lebanon, Bahrain, Qatar, Tunisia and Gaza strip prenatal screening is mandatory and among them, in most of these countries, therapeutic abortion within the $1^{\text {st }}$ four months of gestation is permitted for severe fetal disorders, ${ }^{24,25}$ as most of the Muslims believe that life does not begin at conception, it requires some weeks for perfect instigate of life after development of the primitive streak ${ }^{39}$ In our country, we need religious and legal security for prenatal diagnosis and 
therapeutic interruption of pregnancy as these are the main obstacles. On the other hand, in this situation, a wide panel of psychological distress like refusal of acceptance, feeling guilty or shame, feeling of having stigma, fear of being punished and ultimately frustration may occur. To face this critical situation, elaborate counseling along with psychological support should be given to the couple for choosing the appropriate option available to them. Treating physicians and other related health personnel should be concerned about the privacy, confidentiality to prevent stigmatization.

Finally, the most important challenge is to introduce thalassaemia prevention program into the National preventive program in Bangladesh. As Bangladesh is a developing country, the integrated preventive measures should be organized through the existing healthcare structures and centers. We can also follow the strategy of Cyprus and Sardinia - two unique examples for successful thalassaemia prevention. In Sardinia, a hub and spokes network with a main center and several satellite units was implicated in achieving such success and in Cyprus the similar set-up is also seen. ${ }^{14}$ In Bangladesh, we should establish a national thalassaemia register and referral center immediately. To combat the potential economic barrier, along with government, we also need initiatives and supports from major health organizations and funding agencies.

\section{Conclusion}

The rapidly growing number of children diagnosed as thalassaemia in Bangladesh clearly indicate that thalassaemia will be a emerging health burden in our country. So, we need to prevent thalassaemia before it's too late by comprehensive national integrated prevention programs which include public awareness and education, carrier screening, genetic counseling, premarital screening and prenatal diagnosis. Thalassaemia prevention program became a community concern as it affects marriage practices and reproduction. So, ethical issues need to be addressed for proper implementation by government policy, central control and co-ordination according to the local structures, social values, cultural traditions and religious laws of our country.

\section{References}

1. Modell B, Barlison M. Global epidemiology of haemoglobin disorders and derived service indicator. Bull World Health organ. 2008;86: 480-87.
2. Weatherall DJ. The inherited disease of hemoglobin are an emerging global health burden. Blood. 2010a;115:4331-36.

3. Weatherall DJ. Thalassaemia as a global health problem: Recent progress toward its control in the developing countries. Ann NY Acad Sci. 2010b;1202:17-23.

4. Weatherall DJ, Clegg JB. Inherited Haemoglobin Disorder: an increasing global problem. Bulletin of WHO. 2001;79:704-12.

5. Watherall DJ. The challenge of haemoglobinopathies in resource- poor countries. $\mathrm{Br} \mathrm{J}$ Haematol. 2011;154:736-44.

6. Arifeen SE. Child Health and Mortality. J Health Popul Nutr. 2008;26:273-279.

7. Khan WA. Thalassaemia in Bangladesh. Dhaka Shishu (Children) Hospital Journal. 1999; 15: 42-44.

8. Khan WA, Banu B, Amin SK. Prevealence of ${ }^{2}-$ Thalassaemia Trait \& $\mathrm{Hb}$ trait in Bangladesh School Children and Health Burden of Thalassaemia in our population. Dhaka Shishu (Children) Hospital Journal. 2005; 21: 1-7.

9. Rahman SA, Jamal CY. Congenital Haemolytic Anaemia in Bangladesh: Types and Clinical Manifestations. Indian Pediatrics. 2002; 39: 574-77.

10. Hasan MK, Haque O, Rubaiyat KA, Barshan AD, Talukder SI.Clinical Presentation and Electrophoretic Patterns of Hereditary Haemoglobin Disorders in Adults, a Study at Dinajpur Medical College Hospital. Dinajpur Med Col J. 2013;6:167-71.

11. Farhana DT, Quamrun N, Subhagata C. J Bangladesh Coll Phys Surg. 2009; 27: 148-54.

12. Angastiniotis MA, Hadjiminan MG. Prevention of thalassaemia in Cyprus. Lancet. 1981; 1 : 369-71.

13. Model B, Darlison $M$, Birgens $H$, Cario $H$, Faustino P, Giordano PC, Gulbis B, Hopmeier $P$, Lena-Russo D, Romao L. Epidemiology of haemoglobin disorders in Europe: An overview. Scand J Clin Lab Invest. 2007; 67: 39-69.

14. Co A, Kan YW. The Prevention of Thalassaemia. Cold spring Harb Perspect Med. 2012: 3: a 011775. 
15. Angastiniotis M, Modell B. Global epidemiology of hemoglobin disorders. Ann NY Acad Sci. 1998; 850: 251-69.

16. Mudiyanse RM, Senanayake MP, Rathnayake RMS. "Safe Marriage" for Thalassaemia Prevention: A KAP Survey in Sri Lanka. Transiational Biomedicine. 2015; 6: 26-30.

17. Alwan A, Modell B. Recommendations for introducting genetics services in developing countries. Nat Rev Gent. 2003; 4:61-68.

18. Cao A, Galanello R, Rosatelli MC. Prenatal diagnosis and screening of the haemoglobinopathies. Baillieres Clin Haematol. 1998; 11: 215-238.

19. Fucharoen G, Sanchaisuriya K, Sae-ung N, Dangwibul S, Fucharoen S. A simplified screening stategy for thalassaemia and haemoglobin $E$ in rural communities in Southeast Asia. Bull World Health Organ. 2004; 82: 364-372.

20. Rosatelli C, Falchi AM, Scalas MT, Tuveri T, Furbetta M, Cao A. Hematological phenotype of the double heterozygous state for \pm and $\beta$ thalassemia. Hemoglobin. 1984; 8: 25-35.

21. Saiki RK, Walsh PS, Levwnson $\mathrm{CH}$, Erlich HA. Genetic analysis of amplified DNA with immobilized sequence specific oligonucleotide probes. Proc Natl Acad Sci. 1989; 86: 62306234.

22. Newton CR, Graham A, Heptinstall LE, Powell SJ, Summers C, Kalsheker N, Smith JC, Markham AF. Analysis of any point mutation in DNA. The amplification refractory mutation system (ARMS). Nucleic Acids Res. 1989; 17: 2503-16.

23. Kalokairinou EM. The experience of $\beta$ thalassaemia and its prevention in Cyprus. Med Law. 2007; 26:291-307.

24. Samavat A, Modell B. Iranian national thalassaemia screening programme. BMJ. 2004; 329: $1134-37$.

25. Inati $A$, Zeineh $N$, Ismaeel $H$, Koussa $S$, Gharzuddine W, TaherA. ${ }^{2}$-thalassaemia : The Lebanese experience. Clin Lab Haematol. 2006; 28: 217-27.
26. Amin SK. Prevention of Thalassaemia by Genetic counseling. AKMMC J. 2011; 2: 26-28.

27. Premawardhena A, De Silva S, Arambepola M, Olivieri N, Merson L, Muraco J, Allen A, Fisher $C$, Peto T, Vichinsky E, et al. Thalassemia in Srilanka: A progress report. Hum Mol Genet. 2004;13:203-06.

28. Carlin AJ, Alfirevic Z. Techniques for chorionic villus sampling and amniocentesis: a survey of practice in specialist UK centres. Prenat Diagn. 2008; 28:914-19.

29. Kokkali G, Cram DS, Makrakis E, Trounson AO, Kanavakis E, Pantas K. Blastocyte biopsy versus cleavage stage biopsy and blastocyte transfer for preimplantation genetic diagnosis of $\beta$-thalassaemia: A pilot study. 2007; 22: 14431449.

30. Zachaki S, Vrettou C, Destouni A, Kokkali G, Traegersynodinos J, Kanavakis E. Novel and known microsatellite markers within the ${ }^{2}$-globin cluster to support robust preimplantation genetic diagnosis of ${ }^{2}$-thalassaemia and sickle cell syndromes. Hemoglobin. 2011;35:56-66.

31. Kuliev A, Pakhalchuk T, Verlinsky O, Rechitsky $\mathrm{S}$. Preimplantation genetic diagnosis for haemoglobinopathies. Hemoglobin. 2011;31: 273-77.

32. Xu YW, Zeng YH, Deng J, Liu Y, Gao L, Zhou $C Q$, Zhuang GL. Preimplantation genetic diagnosis for \pm -thalassaemia in chaina. J Assist Report Genet. 2009;26:399-403.

33. Bianchin DW, Williams JM, Sullivan LM, Hanson FW, Klinger KW, Shuber AP. PCR quantitation of fetal cells in maternal blood in normal and aneuploid pregnancies. Am Hum Genet. 1997;61:822-29.

34. Lun FM, Tsui NB, Chan KC, Leung TY, Lau TK, Charoenkwan P, Chow KC, Lo WY, Wanapirak $C$, Sanguansermsri T, et al. Noninvasive prenatal diagnosis of monogenic disease by digital size selection and relative mutation dosage on DNA in maternal plasma. Proc Natl Acad Sci. 2008;105:19920-25.

35. Lo YM, Chan KC, Sun H, Chen EZ, Jiang P, Lun FM, Zheng YW, Leung TY, Lau TK, Cantor CR, et al. Maternal plasma DNA sequencing reveals the genomewide genetic and mutation profile of the fetus. Sci TransI Med. 2010;2:61-91. 
36. Ahmed S, Saleem M, Modell B, Petrou M. Screening extended families for genetic hemoglobin disorder in Pakistan. N Engl J Med. 2002; 347:1162-68.

37. Li DZ.Prenatal screening for thalassemia in mainland Chaina. 2009. Prenat Diagn. 29: 637-38.
38. Sultana GNN, Begum R, Akhter H, Shamim Z, Rahim MA, Chubey G. The Complete Spectrum of Beta $(\beta)$ Thalassemia Mutation in Bangladeshi Population. Austin Biomark Diagn. 2016;3:1024.

39. Serour GI, Dicken BM. Assisted reproductive developments in the Islamic world. International Journal of Gynaecology and Obstetrics. 2001,74:187-93. 